\title{
Are COVID-19 infected children with gastrointestinal symptoms different from those without symptoms? A comparative study of the clinical characteristics and epidemiological trend of $\mathbf{2 4 4}$ pediatric cases from Wuhan
}

Xiao-li Xiong ${ }^{{ }^{*}}$, Kenneth Kak-yuen Wong ${ }^{2 *}$, Shui-qing Chi ${ }^{3 *}$, Ai-fen Zhou ${ }^{4}$, Jian-qiao Tang $^{1}$, Li-Shan Zhou ${ }^{1}$, Patrick Ho-yu Chung ${ }^{2}$, Gilbert T Chua ${ }^{5}$, Keith TS Tung ${ }^{5}$, Ian CK Wong ${ }^{6,7}$, Celine SL Chui ${ }^{5,6}, \mathrm{X} \mathrm{Li}^{5,6}$, Mike Yat-wah Kwan ${ }^{8}$, Wilfred Hing-sang

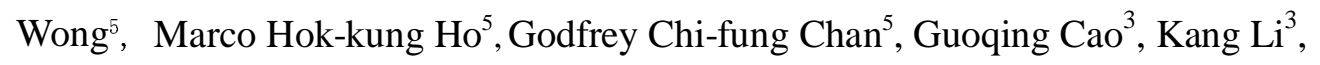
Patrick Ip ${ }^{5 \#}$, Peng Chen ${ }^{9 \#}$, Shao-tao Tang ${ }^{3 \#}$, Paul Kwong-hang Tam ${ }^{2,10 \#}$

${ }^{1}$ Department of Integrated Chinese and Western Medicine, Wuhan Children's Hospital (Wuhan Maternal and Child Healthcare Hospital), Tongji Medical College, Huazhong University of Science and Technology, Wuhan, China

${ }^{2}$ Department of Surgery, LKS Faculty of Medicine, The University of Hong Kong

${ }^{3}$ Department of Paediatric Surgery, Union Hospital, Tongji Medical College, Huazhong University of Science and Technology, Wuhan, China

${ }^{4}$ Department of Maternal Healthcare, Wuhan Children's Hospital (Wuhan Maternal and Child Healthcare Hospital), Tongji Medical College, Huazhong University of Science and Technology, Wuhan, China

${ }^{5}$ Department of Paediatrics \& Adolescent Medicine, LKS Faculty of Medicine, The University of Hong Kong

${ }^{6}$ Centre for Safe Medication Practice and Research, Department of Pharmacology and Pharmacy, LKS Faculty of Medicine, The University of Hong Kong

${ }^{7}$ Research Department of Practice and Policy, UCL School of Pharmacy, University College, London, United Kingdom

${ }^{8}$ Department of Paediatrics and Adolescent Medicine, Princess Margaret Hospital, Hong Kong SAR China

${ }^{9}$ Department of Respiratory Medicine, Wuhan Children's Hospital (Wuhan Maternal and Child Healthcare Hospital), Tongji Medical College, Huazhong University of Science and Technology, Wuhan, China 
${ }^{10}$ Dr. Li Dak Sum Research Centre, The University of Hong Kong-Karolinska Institutet

Collaboration in Regenerative Medicine, The University of Hong Kong

* X Xiong, KKY Wong, \& S Chi are co-first authors

\section{\#Corresponding authors:}

Prof. Paul KH Tam

Department of Surgery,

LKS Faculty of Medicine,

The University of Hong Kong,

Hong Kong, HKSAR China

Tel: +852 22554850

Email: paultam@hku.hk

Prof. ST Tang

Department of Pediatric Surgery

Union Hospital

Tongi Medical College, Huazhong University of Science and Technology

Wuhan, China

Tel: +862762723812

Email: tshaotao83@hust.edu.cn

Prof. Peng Chen

Department of Respiratory medicine

Wuhan Children Hospital (Wuhan Maternal and Child Healthcare Hospital), Wuhan

Tongji Medical College, Huazhong University of Science and Technology

Wuhan, China

Tel: +8613971107002

Email: longting2010@yeah.net

Dr. Patrick Ip

Department of Paediatrics

LKS Faculty of Medicine

The University of Hong Kong,

Hong Kong, HKSAR China

Tel: +852 22554090

Email: patricip@hku.hk 
Contributors Acquisition, analysis and interpretation of data: XX, KW, SC, AZ, JT, LZ; drafting the work or revising it critically for important intellectual content: KW, PC, GC, KT, IW, CC, XL, MK, GC, KL, WW, MH, GC; final approval of the version published, agreement to be accountable for all aspects of the work in ensuring that questions related to the accuracy or integrity of any part of the work: PI, PC, ST, PT

\section{Word count: 1956}




\begin{abstract}
Objective: COVID-19 patients presenting with gastrointestinal (GI) symptoms occur in both adults and children. To date, however, no large sample size study focusing on gastrointestinal symptoms in pediatric cases has been published. We analyzed COVID-19 infected children in Wuhan who presented with initial GI symptoms to determine the GI characteristics and epidemiological trend of the disease.
\end{abstract}

Design: We retrospectively analyzed 244 children patients confirmed with COVID-19 at Wuhan Children's Hospital from 21 Jan to 20 Mar 2020. Symptomatic cases were divided into two groups according to whether the patients presented with or without GI symptoms on admission. Demographic, epidemiological, symptoms, and laboratory data were compared. We also analyzed the respective trends of case number changes of GI cases and asymptomatic cases.

Results: 34 out of 193 symptomatic children had GI symptoms. They had lower median age and weight, a higher rate of fever, a longer length of stay and more hematological and biochemical abnormalities than patients without GI symptoms. There was no significant difference in chest CT findings or stool SARS-CoV-2 test positive percentages between the two groups. The number of patients admitted with GI symptoms showed an overall downward trend with time. At the time of writing, 242 patients were discharged, one died, and one critically ill patient was still in the intensive care unit.

Conclusion: COVID-19 infected children with GI symptoms are prone to presenting with more clinical and laboratory abnormalities than patients without GI symptoms. More attention and timely hospital admission are needed for these patients.

Keywords: COVID-19; gastrointestinal; children; symptoms 


\section{Significance of this study}

\section{What is already known on this subject?}

- COVID-19 is now a pandemic with more than 1.6 million people infected worldwide

- Although attacking the respiratory tract mostly, both adult and children infected with COVID-19 can present with GI symptoms

\section{What are the new findings?}

- Infants younger than two years old and presence of fever are the two risk factors of presenting with GI symptoms

- A high proportion of patients without GI symptoms and asymptomatic patients will have positive RT-PCR for the virus in stool

- Earlier testing through contact screening of family members means more COVID-19 infected children are diagnosed when completely asymptomatic

\section{How might it impact on clinical practice in the foreseeable future?}

- The presence of COVID-19 in stool in infected children will have a major implication for parents and carers of young infants

- Increasing number of asymptomatic COVID-19 patients who are detected through screening could provide a useful lesson for other countries still experiencing the rise and peak of the pandemic 


\section{Introduction}

COVID-19 was first confirmed in Wuhan, Hubei province in December 2019, and has rapidly become a global disease of epic scale in less than two months. As of to date, this pandemic has still not been well controlled, [1, 2, 3] Similar to the Severe Acute Respiratory Syndrome (SARS) in 2003, apart from respiratory manifestations, a proportion of COVID-19 patients also develop GI symptoms, such as diarrhea and vomiting. [4, 5] Several retrospective studies have described the clinical symptoms, epidemiologic characteristics, and outcomes of the patients with GI symptoms, but these have mainly focused on the adult population. [6, 7, 8, 9] It is still not known whether children with COVID-19 have similar or different GI features as adults. Furthermore, some recent studies reported the identification of asymptomatic COVID-19 patients. This has raised the possibility and risk of disease transmission by these patients as silent carriers. [10,11] In this cohort, some patients were diagnosed as asymptomatic infection as well. The main purpose of this study was to describe the gastrointestinal clinical characteristics, to compare the differences between patients with and without GI symptoms, and to find out the epidemiological trend of COVID-19 children in Wuhan.

\section{Methods}

\section{Study design and patients}

This was a retrospective single-center study approved by the Research Ethics Board of Wuhan Children's Hospital (WHCH2020022). Between 21 Jan 2020 and 20 Mar 2020, 244 patients with positive real-time reverse transcription-polymerase chain reaction (RT-PCR) results for COVID-19 from the laboratory department or Wuhan Center for Disease Control and Prevention for nasopharyngeal swab specimens were included. For patients confirmed to have COVID-19, they were divided into five sub-types, according to The Second Edition of Children's COVID-19 Infection Diagnosis, Treatment, and Prevention Guidelines:[12] 1. Asymptomatic - patients without any symptom or abnormal radiography finding. 
2. Acute upper respiratory tract infection - patients presenting with fever, cough, sore throat, fatigue, or other symptoms without pneumonia symptoms on radiography examinations.

3. Mild pneumonia type - patients diagnosed when computed tomography (CT) of the thorax showed any finding of viral pneumonia.

4. Severe type - patients meeting at least one of the following criteria: i) Precluding the influence of high fever and crying, respiratory rate $(R R) \geq 60 /$ min (for children $<2$ months old); RR $\geq 50 /$ min (2-12 months old); RR $\geq 40 /$ min (1-5 years old); RR $\geq$ 30/min (>5 years old); ii) Resting oxygen saturation $\leq 92 \%$; iii) Dyspnea; iv)

Disturbance of consciousness, such as drowsiness or convulsions; v) Dehydration symptoms; vi) High-resolution CT showing rapidly progressive pneumonia or pleural effusion.

5. Critically ill patients - patients meeting any of the following criteria: i) respiratory failure which requires mechanical ventilation; ii) septic shock; iii) multiple organ dysfunction syndromes (MODS).

Symptomatic patients were divided into two groups according to whether the patients had GI symptoms at presentation or not. Patients with GI symptoms were those having at least one of the following before admission: diarrhea (passing of loose stools >3 times per day); nausea and vomiting; abdominal pain; and anorexia. The medical records of all the patients were reviewed. The presenting symptoms, clinical classifications, nucleic acid positive duration, laboratory data, radiography reports, admission date, clinical progress and length of stay (LOS) were recorded. Patients were only discharged when their nasopharyngeal swab RT-PCR results turned negative at least twice on consecutive days.

\section{Patient and Public Involvement}

Patients or the public WERE NOT involved in the design, or conduct, or reporting, or dissemination plans of our research

\section{Statistical analysis}


Categorical variables were described as frequencies and percentages; continuous variables were described as mean (standard deviation) or median (interquartile range) according to the distribution of the data. Significant differences between two groups were tested by Pearson's Chi-squared test for categorical variables, and Mann-Whitney U test or Student t-test for continuous variables. Univariate analysis for odds to presenting GI symptoms was performed by logistic regression for possible confounders from the comparison of patients with or without GI symptoms. Then a multivariable logistic regression model was built considering all significant variables from the univariate regression. Results were presented as odds ratio (OR) [95\% confidence interval]. The data was analyzed by SPSS 26.0 , and $\mathrm{P}<0.05$ was used to determine significance.

\section{Results}

Of the 244 children, 51 patients were asymptomatic. Thus, 193 symptomatic patients were divided into two groups according to whether they had GI symptoms or not on admission. Thirty-four patients (17.7\%) presented with GI symptoms, and the other 159 patients (82.3\%) did not have any GI symptoms on admission (Figure 1). Many patients indeed presented with more than one GI symptoms: 23 (9.47\%) had vomiting, $15(6.17 \%)$ had diarrhea, 8 (3.29\%) had anorexia, and 4 (1.65\%) patients had abdominal pain.

The two groups of patients were similar with respect to sex, birth weight, the percentage of patients in each COVID-19 clinical classification, and the percentage with contact history with an infected family member. The median of age at presentation and the age distribution were significantly different between the two groups. The patients with GI symptoms were much younger (14 vs. 74 months; $P<0.05$ ), and more than half were under three years old (Table 1).

We then compared the clinical and laboratory parameters between the two groups of patients. For the panel of non-GI symptoms, the only significant difference found was that patients with GI symptoms were more likely to have fever on admission $(70.6 \%$ 
vs. $46.2 \%, \mathrm{P}<0.05)$. Although the LOS was slightly longer in the GI group, (12.5 vs. 11.5 days), this did not reach statistical significance. No other significant differences were found between the two groups in other symptoms. Neither the duration of RT-PCR positivity for COVID-19, nor computer tomography (CT) of the thorax was significant between the two groups (Table 2.1). One result of interest was the high rate of positivity of stool SARS-CoV-2 RT-PCR, even in patients without any GI symptoms (37.1\%) and asymptomatic patients (31.6\%).

For the blood tests done on admission, which included complete blood picture, liver and renal function tests and clotting profile, the only statistical differences seen were in neutrophil count, total protein, albumin, ALT, AST and creatinine. However, all these values were still within the normal reference range. The same was also true for cytokine profile and inflammatory markers (Table 2.2).

At the time writing, 242 patients were discharged. One patient died of viraemia and multi-organ failure, one initially critically ill patient was still in the intensive care unit.

In order to ascertain what factors on admission could predict GI symptoms in COVID-19 patients, we employed univariate analysis. This identified several indicators: age; fever, neutrophils, AST, and IL-10. However, when we probed further using multivariable analysis, the only factors which were significant were age and presence of fever (Table 3).

To review the overall trend of our patients with GI symptoms, we plotted our whole cohort according to the admission dates. The median admission date was $18^{\text {th }}$ February. There were significantly more GI cases in patients admitted before this date than after (26 vs. $7 ; \mathrm{P}<0.001)$. Conversely, the patients admitted after $18^{\text {th }}$ February were mostly asymptomatic cases (47 vs. 4 ; $\mathrm{P}<0.001)$ (Figure 2).

\section{Discussion}

Several previous studies showed that GI symptoms were important in COVID-19 patients, and the fecal-oral route could be a possible route of transmission by SARS-CoV-2.[13] Furthermore, both adult and paediatric patients have been reported 
to have prolonged viral shedding in the faeces even when asymptomatic.[14,15] Thus, they will have an impact on an increased prevalence of this pandemic.[6, 16] To date, there is no large sample size study examining the impact of GI symptoms in children with COVID-19 and this study is to our knowledge the first to compare specifically paediatric patients with GI symptoms with those without GI symptom.

In our cohort, $17.7 \%$ presented with GI symptoms on admission, which is slightly higher than the $11.6 \%$ in an adult series.[7] While diarrhea was the most common complaint in adults $(24.2 \%)$, vomiting $(9.47 \%)$ was the predominant symptom, in children. $[6,7,9]$ The reason for the higher rate of GI symptoms in children may be the difficulty in maintaining good hand hygiene in children who are more likely to touch their lips and mouth than adults. Supporting this, we found that infants (younger than two years old) were more likely to present with GI symptoms than older children. One more possible explanation for the higher incidence in younger children may be their less mature systemic and intestinal immunity.[17]

A study focusing on GI symptoms in COVID-19 adults noted that GI cases had a significantly higher rate of fever and a higher tendency to have a more severe disease.[6] In the current study for children, the results further support the association with fever, but not in terms of severity. The difference may be due to a small sample size in children and the extremely low incidence of severe COVID-19 cases in children, which was only $1.65 \%$ in this cohort. The presence of GI symptoms in children did not translate to significantly longer length of stay.

For laboratory abnormalities mainly concentrated on liver function and cytokines tests, significant abnormalities, including increases in AST, IL-10 and decreases in neutrophil, total protein and albumin were identified. Similar abnormalities had been described in the severe or critically ill case series reported previously.[18] These findings suggested that patients with GI symptoms might have more active inflammation especially in the liver. The absence of any significant difference in fecal nucleic acid RT-PCR between children with or without GI symptoms is in agreement with the findings of the adult cohort of Lin et al.[7] In fact, a high proportion of asymptomatic children were found to have positive RT-PCR for the virus in stool. 
Although the detection of viral RNA without additional virological evidence, such as culture or detection of anti-genomic RNA, does not necessary imply infection, this nonetheless should alert us that contact precaution should be exercised in dealing with the excreta of patients with SARS-CoV-2, no matter that they have GI symptoms or not.

Several studies suggested that there might be an increasing trend in adults to present with GI symptoms, from about 3\% reported in January to over $10 \%$ in February.[4, 8] However, our study in children showed a reverse trend. Three-quarters of the patients with GI symptoms were admitted before the median admission date.

This means over the course of the epidemic, fewer patients developed GI symptoms and more asymptomatic patients were diagnosed with passage of time. Whether it is related to the change of viral virulence or isolation policy remains to be further explored. Another observation is that most of the children were infected via family contact rather than community acquired.[16] In our cohort, 203 (83.1\%) of 244 patients were infected by their parents or grandparents. As the epidemic progressed in Wuhan, diagnostic tests became more readily available leading to earlier disease detection through contact screening of family members before they became symptomatic. This observation could be useful for public health planning in countries still experiencing the early stage of the pandemic.

There are limitations of this study. This is a retrospective cohort study so we may not be able to establish any causal relationship. The sample size of patients with GI symptoms is relatively small, due to its low incidence so we may miss out some risk factors for its occurrence. The laboratory examinations and fecal SARS-CoV-2 RNA detection were not done in all patients and this may generate bias in the data analysis. Our study is one of the largest of its kind, and we showed the differences between clinical and laboratory characteristics of patients with or without GI symptoms, which were different from adults. Both pediatricians and patients need to pay more attention to COVID-19 children with GI symptoms even though they have mild symptoms and stable vital signs. An upward trend in asymptomatic infections also means the public should be on guard at all times. 
medRxiv preprint doi: https://doi.org/10.1101/2020.04.29.20084244; this version posted May 5, 2020. The copyright holder for this preprint (which was not certified by peer review) is the author/funder, who has granted medRxiv a license to display the preprint in perpetuity. It is made available under a CC-BY-NC-ND 4.0 International license. 


\section{Competing Interests Declaration:}

All authors declare no competing interests.

\section{References}

1 Chen N, Zhou M, Dong X,,et al. Epidemiological and clinical characteristics of 99 cases of 2019 novel coronavirus pneumonia in Wuhan, China: a descriptive study. Lancet 2020;395:507-13.

2 Rothan HA, Byrareddy SN. The epidemiology and pathogenesis of coronavirus disease (COVID-19) outbreak. J Autoimmun 2020:102433.

3 Saglietto A, D'Ascenzo F, Zoccai GB, et al. COVID-19 in Europe: the Italian lesson. Lancet 2020;395:1110-1.

4 Huang C, Wang Y, Li X,,et al. Clinical features of patients infected with 2019 novel coronavirus in Wuhan, China. Lancet 2020;395:497-506.

5 Lu X, Zhang L, Du H, et al. SARS-CoV-2 Infection in Children. N Engl J Med 2020. Mar 18. doi: 10.1056/NEJMc2005073.

6 Jin X, Lian JS, Hu JH,,et al. Epidemiological, clinical and virological characteristics of 74 cases of coronavirus-infected disease 2019 (COVID-19) with gastrointestinal symptoms. Gut 2020. Mar 24. pii: gutjnl-2020-320926. doi: 10.1136/gutjnl-2020-320926.

7 Lin L, Jiang X, Zhang Z,,et al. Gastrointestinal symptoms of 95 cases with SARS-CoV-2 infection. Gut 2020. Apr 2. pii: gutjnl-2020-321013. doi:

10.1136/gutjnl-2020-321013.

8 Luo S, Zhang X, Xu H. Don't overlook digestive symptoms in patients with 2019 novel coronavirus disease (COVID-19). Clin Gastroenterol Hepatol 2020. Mar 20. pii: S1542-3565(20)30401-8. doi: 10.1016/j.cgh.2020.03.043.

9 Zhou Z, Zhao N, Shu Y, Han S, Chen B, Shu X. Effect of gastrointestinal symptoms on patients infected with COVID-19. Gastroenterology 2020. Mar 18. pii: S0016-5085(20)30362-0. doi: 10.1053/j.gastro.2020.03.020.

10 Bai Y, Yao L, Wei T, Tian F, Jin DY, Chen L, et al. Presumed Asymptomatic Carrier Transmission of COVID-19. JAMA. 2020 Feb 21. doi: 
10.1001/jama.2020.2565.

11 Rothe C, Schunk M, Sothmann P, Bretzel G, Froeschl G, Wallrauch C, et al.

Transmission of 2019-nCoV Infection from an Asymptomatic Contact in Germany. N Engl J Med 2020;382:970-1.

12. Jiang Y, Lu X, Jin R, et al. The Second Edition of Children's COVID-19 Infection Diagnosis, Treatment, and Prevention Guidelines. Chinese Journal of Applied

ClinicalPediatrics.2020,35(2):143-150.DOI:10.3760/cma.j.issn.2095-428X.2020.02.0

12

13. Chen Y, Chen L, Deng Q, Zhang G, Wu K, Ni L, et al The Presence of SARS-CoV-2 RNA in Feces of COVID-19 Patients. J Med Virol. 2020 Apr 3. doi: 10.1002/jmv.25825.

14. Wu Y, Guo C, Tang L, et al. Prolonged presence of SARS-CoV-2 viral RNA in faecal samples. Lancet Gastroenterol Hepatol. 2020 May;5(5):434-435. doi:

$10.1016 / \mathrm{S} 2468-1253(20) 30083-2$.

15. Xu, Y., Li, X., Zhu, B. et al. Characteristics of pediatric SARS-CoV-2 infection and potential evidence for persistent fecal viral shedding. Nat Med 2020:26, 502-505.

https://doi.org/10.1038/s41591-020-0817-4

16. Tian Y, Rong L, Nian W, He Y. Review article: gastrointestinal features in COVID-19 and the possibility of faecal transmission. Aliment Pharmacol Ther. 2020 May;51(9):843-851. doi: 10.1111/apt.15731..

17. Lee PI, Hu YL, Chen PY, et al. Are children less susceptible to COVID-19? J

Microbiol Immunol Infect. 2020 Feb 25. pii: S1684-1182(20)30039-6. doi:

10.1016/j.jmii.2020.02.011.

18. Sun $\mathrm{D}, \mathrm{Li} \mathrm{H}, \mathrm{Lu} \mathrm{XX}$, et al. Clinical features of severe pediatric patients with coronavirus disease 2019 in Wuhan: a single center's observational study. World J Pediatr. 2020 Mar 19. doi: 10.1007/s12519-020-00354-4. 
Table 1. Demographics and epidemiological characteristics of COVID-19 children with or without GI symptoms

\begin{tabular}{|c|c|c|c|}
\hline & GI symptoms $(n=34)$ & $\begin{array}{c}\text { Non-GI symptoms } \\
(n=159)\end{array}$ & P-value \\
\hline \multicolumn{4}{|l|}{ Age (months) } \\
\hline Median (IOR) & $14(3-93)$ & $74(13-122)$ & $0.013^{*}$ \\
\hline Age group distribution & & & $0.020 *$ \\
\hline 0- 1 month & $2(5.88 \%)$ & $8(5.03 \%)$ & \\
\hline 1 month-12 months & $14(41.18 \%)$ & $29(18.24 \%)$ & \\
\hline 1-3 years old & $4(11.76 \%)$ & $20(12.58 \%)$ & \\
\hline $3^{-6}$ years old & $3(8.82 \%)$ & $19(11.95 \%)$ & \\
\hline $6-10$ years old & $5(14.71 \%)$ & $43(27.04 \%)$ & \\
\hline $10-18$ years old & $6(17.65 \%)$ & $40(25.16 \%)$ & \\
\hline Sex (male) & $19(55.88 \%)$ & $101(63.52 \%)$ & 0.404 \\
\hline Birth Weight (kg) & $3.30(2.93-3.70)$ & $3.30(3.00-3.55)$ & 0.948 \\
\hline \multicolumn{3}{|c|}{ Clinical Diagnostic Classification } & 0.465 \\
\hline $\begin{array}{c}\text { Acute upper respiratory } \\
\text { infection }\end{array}$ & $7(20.59 \%)$ & $43(27.04 \%)$ & \\
\hline Mild Pneumonia & $25(73 \cdot 53 \%)$ & $107(67.30 \%)$ & \\
\hline Severe Pneumonia & $0(0 \%)$ & $7(4.40 \%)$ & \\
\hline Critical Pneumonia & $2(5.88 \%)$ & $2(1.26 \%)$ & \\
\hline $\begin{array}{l}\text { Contact History with } \\
\text { Infected Family Member }\end{array}$ & $27(79.41 \%)$ & $132(83.02 \%)$ & 0.616 \\
\hline
\end{tabular}


Table 2.1 Clinical and radiological characteristics of COVID-19 children with or without Gl symptoms

\begin{tabular}{|c|c|c|c|}
\hline & GI symptoms $(n=34)$ & $\begin{array}{c}\text { Non-GI symptoms } \\
(n=159)\end{array}$ & P-value \\
\hline \multicolumn{4}{|l|}{ Symptoms } \\
\hline Fever & $24(70.59 \%)$ & $75(46.17 \%)$ & $0.013 *$ \\
\hline Cough & $17(50.00 \%)$ & $103(64.78 \%)$ & 0.107 \\
\hline Sputum Production & $2(5.88 \%)$ & $23(14.47 \%)$ & 0.176 \\
\hline Runny Nose & $4(11.76 \%)$ & $20(12.58 \%)$ & 0.896 \\
\hline Fatigue & $1(2.94 \%)$ & $7(4.40 \%)$ & 0.698 \\
\hline Dyspnea & $2(5.88 \%)$ & $9(5.66 \%)$ & 0.960 \\
\hline Sore Throat & $2(5.88 \%)$ & $8(5.03 \%)$ & 0.839 \\
\hline Headache & $4(11.76 \%)$ & $6(3 \cdot 77 \%)$ & 0.056 \\
\hline Dizziness & $1(2.94 \%)$ & $2(1.26 \%)$ & 0.471 \\
\hline Myalgia & $3(8.82 \%)$ & $6(3.77 \%)$ & 0.205 \\
\hline Chest Distress & $2(5.88 \%)$ & $9(5.66 \%)$ & 0.960 \\
\hline Edema & $0(0 \%)$ & $2(1.26 \%)$ & 0.511 \\
\hline Convulsion & $1(2.94 \%)$ & $1(0.63 \%)$ & 0.227 \\
\hline Chills & $0(0 \%)$ & $2(1.26 \%)$ & 0.511 \\
\hline Length of Stay (days) & $12.50(8.00-17.00)$ & $11.5(8.75-16.00)$ & 0.646 \\
\hline Nucleic acid Positive & $7.00(5.00-10.00)$ & $7.00(5.00-11.00)$ & 0.731 \\
\hline \multicolumn{4}{|l|}{ Duration (days) } \\
\hline \multicolumn{4}{|c|}{ Stool SARS-CoV-2 RT-PCR } \\
\hline \multicolumn{4}{|l|}{ Results } \\
\hline Positive & $7 / 17(41.18 \%)$ & $26 / 70(37.14 \%)$ & 0.759 \\
\hline \multicolumn{4}{|l|}{ Imaging } \\
\hline Pulmonary Lesions & & & 0.287 \\
\hline Null & $9(26.47 \%)$ & $46(28.93 \%)$ & \\
\hline Unilateral & $11(32.35 \%)$ & $68(42.77 \%)$ & \\
\hline Bilateral & $14(41.18 \%)$ & $45(28.30 \%)$ & \\
\hline $\begin{array}{c}\text { Ground-glass } \\
\text { Opacities }\end{array}$ & $6(17.65 \%)$ & $24(15.09 \%)$ & 0.762 \\
\hline
\end{tabular}


Table 2.2 Laboratory characteristics of COVID-19 children with or without GI symptoms

\begin{tabular}{|c|c|c|c|}
\hline & GI symptoms $(n=34)$ & $\begin{array}{c}\text { Non-GI symptoms } \\
(n=159)\end{array}$ & P-value \\
\hline \multicolumn{4}{|l|}{ Complete blood picture } \\
\hline $\begin{array}{l}\text { White blood cell count } \\
\qquad\left(\times 10^{9} / \mathrm{L}\right)\end{array}$ & $6.97(5.39-9.20)$ & $6.75(5.37-8.20)$ & 0.642 \\
\hline Hemoglobin ( $g / L)$ & $122.00(107.00-130.50)$ & $125.50(117.75-133.00)$ & 0.051 \\
\hline Platelets $\left(\times 10^{9} / \mathrm{L}\right)$ & $278.00(200.00-376.00)$ & $\begin{array}{c}288.00 \\
(241.00-368.00)\end{array}$ & 0.502 \\
\hline Neutrophils $\left(\times 10^{9} / \mathrm{L}\right)$ & $1.92(1.07-2.98)$ & $2.61(1.84-3.77)$ & $0.023 *$ \\
\hline Monocytes $\left(\times 10^{9} / \mathrm{L}\right)$ & $0.48\left(0.35^{-0} 0.74\right)$ & $0.42\left(0.35^{-0.56)}\right.$ & 0.146 \\
\hline Lymphocytes $\left(\times 10^{9} / \mathrm{L}\right)$ & $3.49(2.11-5.26)$ & $2.95(1.97-4.04)$ & 0.168 \\
\hline \multicolumn{4}{|l|}{ Liver Function test } \\
\hline Total Bilirubin ( $\mu \mathrm{mol} / \mathrm{L})$ & $6.70(5.10-8.55)$ & $7.70(5.40-9.90)$ & 0.265 \\
\hline Direct Bilirubin $(\mu \mathrm{mol} / \mathrm{L})$ & $1.80(1.30-2.60)$ & $2.20(1.60-3 \cdot 30)$ & 0.055 \\
\hline Total Protein (g/L) & $63.60(57.90-72.60)$ & $68.80(64.30-72.40)$ & $0.038 *$ \\
\hline Albumin (g/L) & $43.90(40.70-46.55)$ & $45.10(43.10-47.70)$ & $0.018 *$ \\
\hline Globulin (g/L) & $21.01 \pm 5.85$ & $23 \cdot 29 \pm 5 \cdot 51$ & 0.756 \\
\hline $\begin{array}{l}\text { Alanine aminotransferase } \\
\qquad(\mathrm{U} / \mathrm{L})\end{array}$ & $22.00(13.75-31.75)$ & $15.00(11.00-28.00)$ & $0.015^{*}$ \\
\hline $\begin{array}{c}\gamma \text {-glutamyl transpeptidase } \\
(\mathrm{U})\end{array}$ & $14.00(8.00-31.00)$ & $11.00(9.00-16.00)$ & 0.261 \\
\hline $\begin{array}{l}\text { Aspartate aminotransferase } \\
\qquad(\mathrm{U} / \mathrm{L})\end{array}$ & $42.50(26.00-62.25)$ & $30.00(23.00-42.00)$ & $0.002 *$ \\
\hline alkaline phosphatase $(U)$ & $186.00(148.00-265.00)$ & $\begin{array}{c}194.00 \\
(157.00-244.00)\end{array}$ & 0.745 \\
\hline \multicolumn{4}{|l|}{ Renal Function test } \\
\hline $\begin{array}{l}\text { Blood urea nitrogen } \\
\qquad(\mathrm{mmol} / \mathrm{L})\end{array}$ & $3.85(2.89-4.60)$ & $4.00(3.20-4.68)$ & 0.656 \\
\hline Creatinine $(\mu \mathrm{mol} / \mathrm{L})$ & $24.25(19.10-38.08)$ & $33.20(25.85-45.10)$ & $0.006 *$ \\
\hline
\end{tabular}




\begin{tabular}{|c|c|c|c|}
\hline Prothrombin Time (s) & $10.70(10.40-11.35)$ & $10.90(10.60-11.38)$ & 0.384 \\
\hline PT-INR & $0.91(0.88-0.96)$ & $0.93(0.89-0.97)$ & 0.191 \\
\hline D-Dimer (mg/L FEU) & $0.27(0.14-0.63)$ & $0.22(0.13-0.36)$ & 0.289 \\
\hline Antithrombin (\%) & $112.30(103.90-121.80)$ & $\begin{array}{c}116.90 \\
(106.80-123.20)\end{array}$ & 0.221 \\
\hline Fibrinogen $(\mathrm{g} / \mathrm{L})$ & $2.15(1.84-2.34)$ & $2.15(1.87-2.75)$ & 0.267 \\
\hline $\begin{array}{c}\text { Activated Partial } \\
\text { Thromboplastin Time (s) }\end{array}$ & $30.80(28.40-38.30)$ & $30.85(28.70-34.00)$ & 0.489 \\
\hline Thrombin Time (s) & $18.00(17.60-18.85)$ & $18.30(17.43-19.38)$ & 0.614 \\
\hline \multicolumn{4}{|l|}{ Cytokines } \\
\hline $\mathrm{IL}-2(\mathrm{pg} / \mathrm{ml})$ & $1.46(1.26-1.82)$ & $1.43(1.22-1.70)$ & 0.705 \\
\hline $\mathrm{IL}-4(\mathrm{pg} / \mathrm{ml})$ & $2.66(2.16-3.24)$ & $2.62(2.10-3.27)$ & 0.876 \\
\hline $\mathrm{IL}-6(\mathrm{pg} / \mathrm{ml})$ & $5.08(2.95-14.31)$ & $3.92(2.95-6.67)$ & 0.117 \\
\hline $\mathrm{IL}-10(\mathrm{pg} / \mathrm{ml})$ & $5.21(3.37-8.81)$ & $3.80\left(3.23-4.5^{8}\right)$ & $0.018 *$ \\
\hline TNF- $\alpha(p g / m l)$ & $1.83(1.59-2.22)$ & $1.62(1.21-2.19)$ & 0.097 \\
\hline $\mathrm{IFN}-\gamma(\mathrm{pg} / \mathrm{ml})$ & $3.65(2.86-8.57)$ & $2.89(2.35-4.21)$ & 0.073 \\
\hline \multicolumn{4}{|l|}{ Infection-related } \\
\hline \multicolumn{4}{|l|}{ Biomarkers } \\
\hline Procalcitonin (ng/ml) & $0.07(0.04-0.11)$ & $0.05\left(0.04^{-0.08)}\right.$ & 0.125 \\
\hline C-reactive protein $(\mathrm{mg} / \mathrm{l})$ & $0.75(0.75-5.05)$ & $0.75(0.75-2.97)$ & 0.597 \\
\hline $\begin{array}{l}\text { Erythrocyte sedimentation } \\
\text { rate }(\mathrm{mm} / \mathrm{h})\end{array}$ & $6.50(3.50-14.50)$ & $10.00(3.00-19.00)$ & 0.437 \\
\hline
\end{tabular}


medRxiv preprint doi: https://doi.org/10.1101/2020.04.29.20084244; this version posted May 5, 2020. The copyright holder for this preprint (which was not certified by peer review) is the author/funder, who has granted medRxiv a license to display the preprint in perpetuity. It is made available under a CC-BY-NC-ND 4.0 International license.

Table 3. Univariate and multivariate logistic regression for odds to GI symptoms

\begin{tabular}{|c|c|c|c|c|}
\hline $\begin{array}{l}\text { Logistic Regression for } \\
\text { odds to GI symptoms }\end{array}$ & $\begin{array}{c}\text { Univariate OR }(\mathrm{Cl} \\
95 \%)\end{array}$ & P-value & $\begin{array}{l}\text { Multivariable OR } \\
\qquad(\mathrm{Cl} 95 \%)\end{array}$ & P-value \\
\hline $\begin{array}{l}\text { Age ( }>24 \text { months old } \\
\text { vs. }<24 \text { months old) }\end{array}$ & $3.209(1.501-6.860)$ & $0.003^{*}$ & $3.208(1.163-8.852)$ & $0.024 *$ \\
\hline Fever (novs. yes) & $2.688(1.207-5.987)$ & $0.016^{*}$ & $3.638\left(1.219-10.85^{8}\right)$ & $0.021 *$ \\
\hline $\begin{array}{c}\text { Neutrophils count } \\
\text { (reference normal } \\
\text { range) }\end{array}$ & $0.275(0.107-0.705)$ & $0.007^{*}$ & $0.878(0.239-3.223)$ & 0.844 \\
\hline $\begin{array}{c}\text { AST (reference normal } \\
\text { range) }\end{array}$ & $3.5^{8} 4(1.548-8.302)$ & $0.003^{*}$ & $2.33^{8}(0.661-8.276)$ & 0.187 \\
\hline $\begin{array}{l}\text { IL-10 (reference normal } \\
\text { range) }\end{array}$ & $4.016(1.618-9.967)$ & $0.003^{*}$ & $1.527(0.505-4.623)$ & 0.453 \\
\hline
\end{tabular}




\section{Figure legends}

Figure 1 - A flowchart showing the cohort of 244 paediatric patients infected with COVID-19.

Figure 2 - A graph showing the total number of paediatric patients (line), the number of patients admitted with GI symptoms (solid bar) and the number of patients admitted without GI symptoms (blank bar) infected with COVID-19 between $21^{\text {st }}$ January to $20^{\text {th }}$ March 2020. 
Patients confirmed with COVID-19 $(\mathrm{n}=244)$

With GI symptoms $(\mathrm{n}=34)$

Without GI symptoms $(\mathrm{n}=159)$ 
